\title{
Çok düzlemli kablo fiksasyon sisteminin biyomekanik dayanıklıı̆̆ının araştırılması
}

\author{
Investigation of biomechanical stability of multi-plane cable fixation system \\ Seyran Kılınç*, Okay Bulut, Gündüz Tezeren, Hayati Öztürk, Zekeriya Öztemur
}

Ortopedi ve Travmatoloji Kliniği (Dr. S. Kılınç) Harput Devlet Hastanesi, TR-23200 Elazı̆̆ Ortopedi ve Travmatoloji Anabilim Dalı (Prof. Dr. O. Bulut, Prof. Dr. G. Tezeren, Doç. Dr. H. Öztürk, Yrd. Doç. Dr. Z. Öztemür), Cumhuriyet Üniversitesi Tıp Fakültesi, TR-58140 Sivas

\section{Özet}

Amaç. Çok düzlemli kablo fiksasyon sisteminin biyomekanik dayanıklılığının araştırılması. Yöntem. Çalışmada 12 adet dana femur kemiğine subtrokanterik oblik osteotomi yapılarak standart kablo fiksasyon sistemi ve çok düzlemli kablo fiksasyon sistemi ile tespit edildikten sonra aksiyel kompresyon testleri uygulandı. Bulgular. Yöntemlere ait kompresyon kuvvet değerlerinin aritmetik ortalaması standart kablo fiksasyon sistemi için 787,33 N, çok düzlemli kablo fiksasyon sistemi için 1631,66 N olarak ölçüldü. Gruplara ait tespit yetersizliği ölçümleri karşılaştırıldığında gruplar arası farklılık anlamlı bulundu $(\mathrm{p}<0.05)$. Sonuç. Kırık yada osteotomi hattının çok düzlemli uzanımlarının önceden öngörülememesi, standart kablo fiksasyon sisteminin tek bir düzlemde fiksasyona izin vermesi ve metafizer metafizo-diafizer bölgede gevşemesi nedeni ile çok düzlemli kablo fiksasyon sistemi bu sorunların giderilmesinde mutlak bir üstünlük sağlamaktadır.

Anahtar sözcükler: Kablo fiksasyon, periprostetik kırık, tespit yetersizliği, osteotomi fiksasyon

\begin{abstract}
Aim. Research of bio-mechanical stability of multi-plane cable fixation system. Method. In this study, axial compression tests were applied, after 12 calf femur bone was fixed with standard cable fixation system and multi-plane cable fixation system by subtrochanteric osteotomy. Results. Arithmetic mean of compression force values of technics were measured for standard cable fixation system as $787,33 \mathrm{~N}$, for multi-plane cable fixation system as 1631,66 N. When fixation inadequacy measurements was compared, difference of between groups shows correlation. $(\mathrm{p}<0.05)$. Conclusion. Due to multi plane elongations of line of fracture or osteotomy can not be foreseen, standard cable fixation system allows fixation on a single plane and relaxed on metaphyseal metaphyso-diaphsial region, Multi-plane cable fixation system provides significant advantage in solving this problem.
\end{abstract}

Keywords: Cable fixation, periprosthetic fracture, fixation insufficiency, osteotomy fixation

Geliş tarihi/Received: 24 Mayıs 2013; Kabul tarihi/Accepted: 04 Ekim 2013

\section{*İletişim adresi:}

Dr. Seyran Kılınç, Ortopedi ve Travmatoloji Kliniğgi, Harput Devlet Hastanesi, TR-23200 Elazı̆̆. E-posta: seyrankilinc@hotmail.com

\section{Giriş}

Çevresel tel tespiti ortopedi ve travmatolojide kırık tespitinde ana veya yardımcı materyal olarak geçmişten beri sıkça kullanılan bir yöntemdir. Ancak geçmişte kullanılan tel sisteminin zayıflığı, daha güçlü fiksasyon cihazı ihtiyacına ve kablo tutucu sistem gelişmesine sebep olmuştur.

Kablo fiksasyon sistemi günümüzde uzun kemik metafizer, metafizo-diafizeal uzun oblik yada spiral kırıklarda, osteotomilerde, revizyon protez cerrahisinde, periprostetik kırıklarda ve bir çok alanda kullanılmakla birlikte tespit stabilitesi ve devamlılı̆̆ bazı 
açılardan sorunludur. Çünkü tesbit stabilitesi ve devamlılığının korunamaması bu denli büyük cerrahi operasyonlar sonrası komplikasyon sıklığının artmasına sebep olmaktadır.

Günümüzde birçok kablo fiksasyon sistemi kullanılmakla birlikte hemen hemen hepsi ortak özellikler taşımaktadır. Bu sistemlerden hiçbiri yumuşak doku desteği ve kemiğin anatomik çıkıntısına dayanmaksızın farklı açılarda tespit sağlayamamaktadır. Kırık tesbiti sırasında her zaman bu gibi yardımcı unsurların olmaması bize farklı açılarda uygulanabilen ve daha stabil kablo fiksasyon sisteminin gereksinimi düşündürmüştür.

Periprostetik femur kırıkları, kalça protezi uygulamalarının geliştirilmeye başlandığı ilk dönemlerinde nadir görülen bir komplikasyonken [1,2]; primer ve revizyon kalça protezi uygulamalarının yaygınlaşması, populasyonun yaşının [1], aktivitesinin ve sağlık düzeyinin artması nedeniyle [3]; ameliyat sırasında $\% 0,3$ ile $\% 21$ arasında ortaya çıkan [4] bir komplikasyon haline gelmiştir [1,3]. Her ne kadar periprostetik kırık bir komplikasyon olsa da tedavi sonunda erken mobilizasyona olanak veren stabil bir tespit sağlamak tedavinin birincil amacını oluşturmaktadır [5]. Literatürde çeşitli yöntemler tarif edilmesine rağmen en uygun ve özgün tedavi yöntemi konusunda görüş birliği yoktur [5, 6].

Ameliyat sırasında oluşan proksimal femurun uzunlamasına kırıkların da tedavi planlamasının uygun biçimde yapılabilmesi için farklı sınıflama yöntemleri oluşturulmuştur [7-9]. Bu tip kırıkların tedavisinde serklaj teli, kablo ve kortikal greftler ile internal fiksasyon [7, 8] ya da uzun stem revizyon protezleri [9] kullanilabileceği bildirilmiştir. Fakat standart kablo fiksasyon sistemi femur proksimal anatomisinin konik yapısı nedeniyle tel kaymasını yeterli engelleyemediğinden, tesbit stabilitesi ve devamlılığının korunmasında büyük problem yaratmaktadır. Çok düzlemli kablo fiksasyon sistemi ile domino ve plak sistemindeki dikenler sayesinde farklı açılarda kablo fiksasyonu yapılabileceğini ve daha stabil kırık tesbiti sağlanabileceğini düşünmekteyiz.

Çalışmamızda femur subtrokanterik bölgede spiral bir kırık modeli oluşturduk. Tasarımı Prof. Dr. Okay BULUT tarafından yapılan ve patent aşamasında olan çok düzlemli kablo fiksasyon sistemi ile standart kablo fiksasyon sistemi kullanarak aksiyel yüklenme altında sağladıkları stabiliteyi biyomekanik testlerle karşılaştırmayı amaçladık.

\section{Gereç ve yöntem}

\section{Grupların oluşturulması}

Çalışmamızda test materyali olarak 18-36 aylık 6 adet dananın 12 femuru in vitro olarak kullanıldı. Bu çalışmanın yapılması, Sivas Cumhuriyet Üniversitesi Hayvan Deneyleri Yerel Etik Kurulu tarafindan 01.04.2010 tarihli ve 50-34 karar numaralı tutanakla uygun bulunmuştur. $\mathrm{Bu}$ çalışma Cumhuriyet Üniversitesi Tıp Fakültesi Ortopedi ve Travmatoloji Anabilim Dalı tarafindan Cumhuriyet Üniversitesi Sivas Meslek Yüksek Okulu Makine Bölümü laboratuvarında yapıldı. Tüm örnekler $18 \pm 2{ }^{\circ} \mathrm{C}$ sıcaklıkta hazırlandı ve test edildi. Çalışmada kullanılan dana femurların farklı büyüklük ve kalınlıkta olması nedeniyle gruplar arasında kemik yoğunlukları açısından fark olmaması için dana femur kemiğin sağ ve sol femurları karşı1ıklı gruplara rastgele seçilerek alındı.

\section{Deneylerde kullanılan standart kablo fiksasyon sistemi}

Standart kablo fiksasyon sistemi olarak multiflaman yapıda $316 \mathrm{~L}$ paslanmaz çelikten 2,0X600 mm boyutunda kablo ve 6X4X8,5 mm boyutunda domino kullanılmıştır (Resim $1)$. 

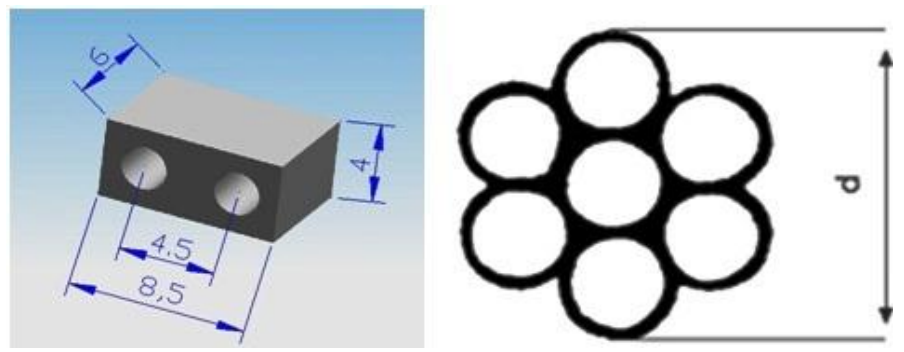

Resim 1. Standart kablo fiksasyon sistemi.

\section{Deneyde kullanılan çok düzlemli kablo fiksasyon sistemi}

Çok düzlemli kablo fiksasyon sistemi olarak multiflaman yapıda $316 \mathrm{~L}$ paslanmaz çelikten 2,0X600 mm boyutunda kablo, kendi geliştirdiğimiz titanyum grade 23 (TI6AL4V ELI) serisinden $28,5 \times 7,75 \mathrm{X} 1 \mathrm{~mm}$ boyutunda her iki ucunda kablonun geçeceği 30 derece açı ile açılmış delikleri olan tabanı $3 \mathrm{~mm}$ uzunluğu $5 \mathrm{~mm}$ konik yapıda iki adet dikenleri olan plak, 316L paslanmaz çelikten 8,48X14X6 mm boyutunda iç kısma gelen eğimli yüzey üzerinde 15 derece acı ile yerleştirilmiş tabanı $3 \mathrm{~mm}$ uzunluğu $5 \mathrm{~mm}$ olan iki adet dikeni olan domino kullanılmıştır (Resim 2).

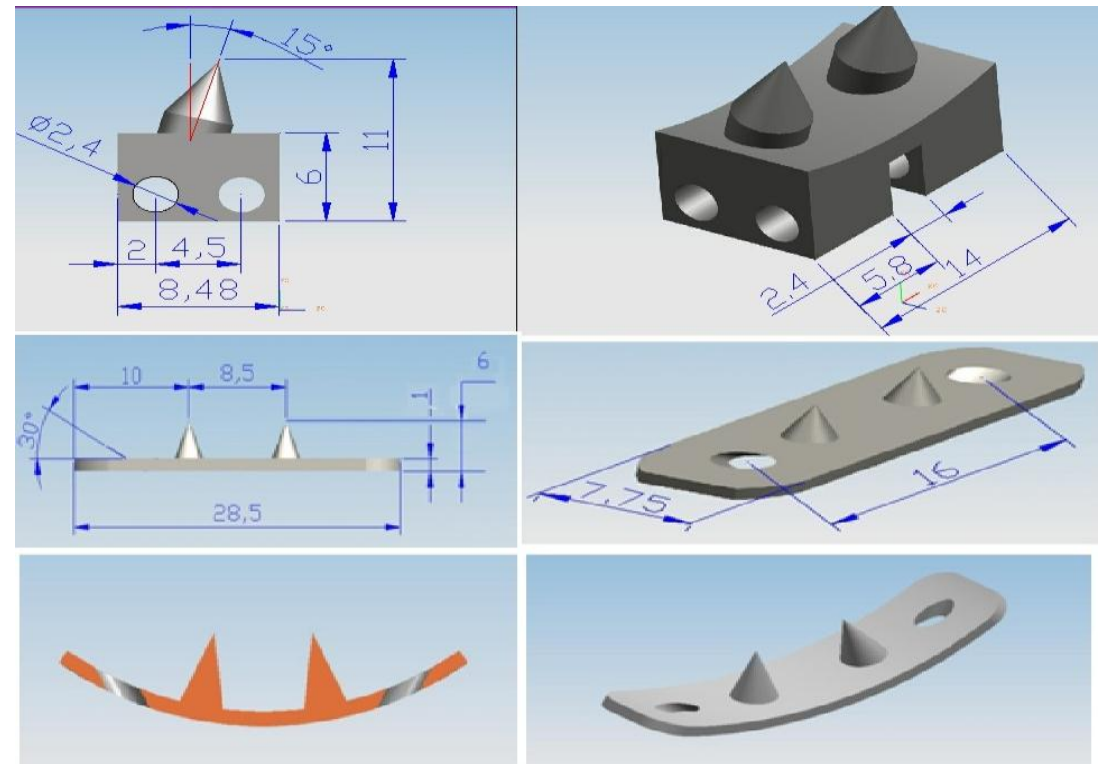

Resim 2. Çok düzlemli kablo fiksasyon sistemi.

\section{Tesbit materyallerin hazırlanması}

Her bir dana femuru trokanter minör seviyesinden çapı kumpas ile ölçüldü. Ölçüm değerinin 1,5 katı uzunluğunda distali medialde proximali lateralde olacak şekilde $1 \mathrm{~mm}$ eninde bıçağı olan elektrikli testere ile $\mathrm{S}$ şeklide oblik osteotomi yapıldı. Femur suprakondiler bölgeden kompresyon cihazına yerleştirmek için transvers olarak osteotomi yapild1.

Standart kablo fiksasyon yöntemi uygulanan grup için, kemik klempleri ile osteotomi hattı redükte edildikten sonra fragmanlar arasında en iyi teması sağlamak için osteotomi hattı üç eşit parçaya bölünerek, her bir kablo tesbiti 1/3' lük kısma gelecek şekilde iki adet kablo ile transvers olarak tespit yapıldı. Tespit yapılırken kablonun gerdirilmesi sirasında distale kaymasını önlemek amacı ile kemiğin medial korteksinde $1 \mathrm{~mm}$ derinliğinde kanal açılarak kablonun bu kanala oturarak distale kayması önlenmeye çalışıldı. Tespit stabilitesi elle kontrol edildi (Resim 3). 


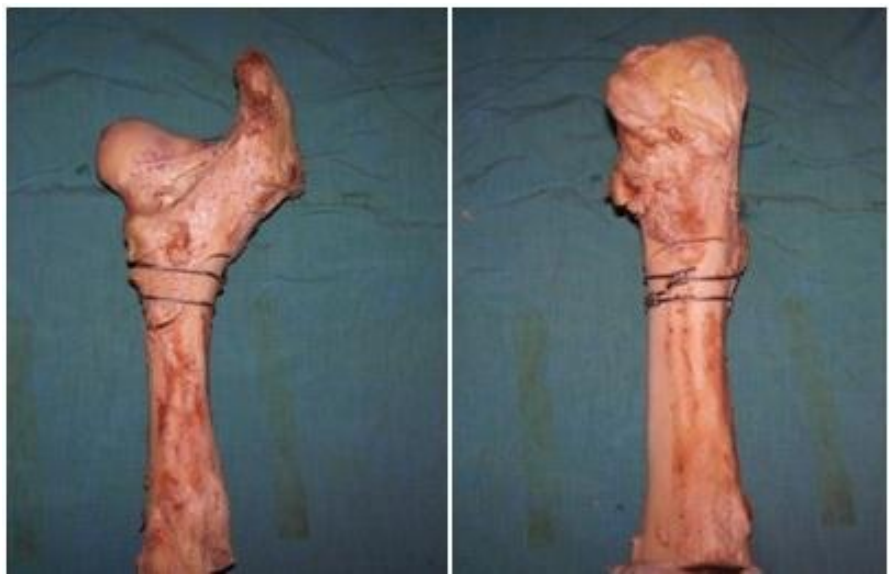

Resim 3. Standart kablo fiksasyon yöntemin ön-arka ve yan görüntüsü.

Çok düzlemli kablo fiksasyon yöntemi uygulanan grup için kemik klempleri ile osteotomi hattı redükte edildikten sonra osteotomi hattı üç eşit parçaya bölündükten sonra iki adet kablo ile osteotomi hattına dik olacak şekilde tespit yapıldı. Medialde plağın ve lateralde dominonun yerleştirilmesi sırasından dana femurun sert kortikal yapısından dolayı 3,2 mm dril ile kanallar açılarak dikenler yerleştirildi. Plak ve dominonun kemiğe tam oturmasını sağlamak için, plak femur korteksine uygun şekilde bükülerek konuldu. Tespit stabilitesi elle kontrol edildi (Resim 4).

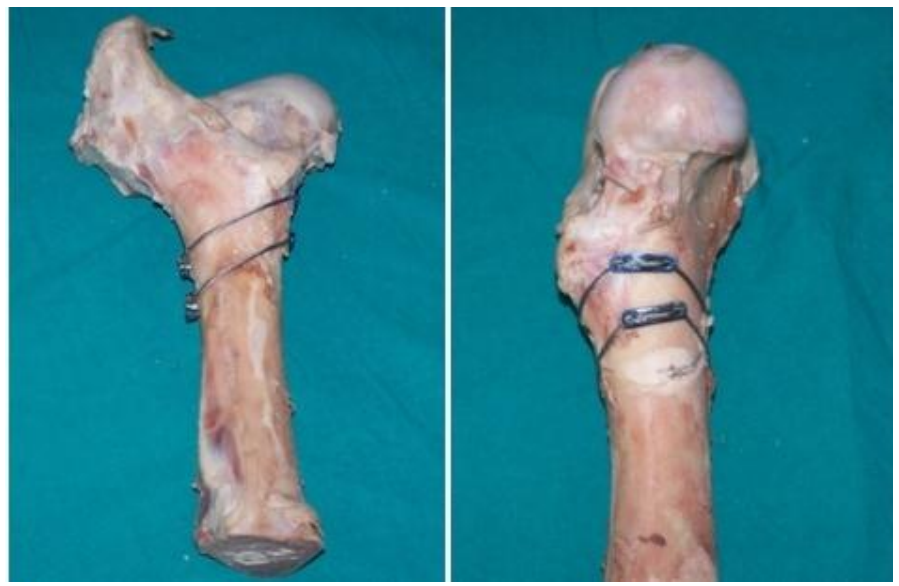

Resim 4. Çok düzlemli kablo fiksasyon yöntemin ön-arka ve yan görüntüsü.

\section{Biyomekanik ölçümler}

Bütün preparatları biyomekanik olarak test etmek için HTI HOUNSFIELD TEST EQUIPMENT LTD, REDHILL, ENGLAND ${ }^{\circledR}$ marka 50.000 Newton kapasiteli kompresyon-distraksiyon cihazı kullanıldı. Kemikler uygun aparatlar kullanılarak kompresyon cihazına konularak cihazın yük alma noktasından itibaren dijital göstergesindeki $2 \mathrm{~mm}$ kompresyonu tespitin yetmezliğini sağlayan kuvvet olarak değerlendirildi.

\section{İstatistiksel yöntem}

Çalışmamızdaki veriler SPSS (Statistical Package forthe Social Sciences), (ver: 14.0) programına yüklenerek, değerlendirilmesinde Mann-Whitney U testi kullanılmıştır. Verilerimiz tablomuzda aritmetik ortalama \pm standart sapma şeklinde belirtilip yanılma düzeyi 0,05 olarak alınmıştır. $\alpha=0,05$ ve $\beta=0,20$ olarak alındığında her iki gruba altışar hayvan alındığında testin gücü $\mathrm{p}=0,97612$ bulundu. 


\section{Bulgular}

İki grup için 2 mm'lik ayrılma noktaları için elde edilen değerler aşağıda gösterilmiştir (Tablo 1).

Tablo 1. Kemik tesbitindeki 2 mm lik yetersizliğe neden olan kuvvetlerin Newton cinsinden değerleri (Newton $(\mathbf{N}))$.

\begin{tabular}{|c|c|c|}
\hline Örnek no & Grup 1 & Grup 2 \\
\hline & $\begin{array}{l}\text { Standart kablo fiksasyon } \\
\text { sistemi(SKF) }\end{array}$ & $\begin{array}{l}\text { Çok düzlemli kablo fiksasyon } \\
\text { sistemi (ÇDKF) }\end{array}$ \\
\hline & $\begin{array}{l}2 \mathrm{~mm} \text { lik ayrılma için gerekli } \\
\text { kuvvet }(\mathrm{N})\end{array}$ & $\begin{array}{l}2 \mathrm{~mm} \text { lik ayrılma için gerekli } \\
\text { kuvvet }(\mathrm{N})\end{array}$ \\
\hline 1 & 500 & 1450 \\
\hline 2 & 1024 & 1500 \\
\hline 3 & 890 & 1820 \\
\hline 4 & 750 & 1900 \\
\hline 5 & 730 & 1570 \\
\hline 6 & 830 & 1550 \\
\hline
\end{tabular}

Gruplar 2 mm'lik ayrılma için gerekli kuvvet yönünden karşılaştırıldığında gruplar arası farkl11ık önemli bulunuştur ( $<<0,05)$. Görüldüğü gibi Çok Düzlemli Kablo Fiksasyon yöntemi uygulanan grupta 2 mm'lik tespit yetersizliği için gerekli kuvvet Standart Kablo fiksayon uygulanan gruptan daha yüksektir (Tablo 2).

Tablo 2. Yöntemlere ait kompresyon kuvvet değerlerinin karşılaştırılması.

\begin{tabular}{ll}
\hline Gruplar & Ayrılma noktası (N) \\
\hline & Aritmetik ortalama \pm Standart sapma \\
\cline { 2 - 2 } Standart kablo fiksasyon sistemi & $787,33 \pm 176,46$ \\
Çok düzlemli kablo fiksasyon sistemi & $1631,66 \pm 183,45$ \\
\hline Sonuç & $\mathrm{p}=0,004$ \\
\hline${ }^{*} \mathrm{p}<0,05$ önemli & \\
\hline
\end{tabular}

\section{Tartışma}

Kablo fiksasyon sistemi için son 30 yılda geliştirilen çok sayıda alet ve teknik, kaynamama ve fragman migrasyonu problemlerinin devam ettiğinin kanitıdır [10]. Günümüzde bir çok kablo fiksasyon sistemi kullanılmakla birlikte hemen hemen hepsi ortak özellikler taşımaktadır. Bu sistemlerden hiçbiri yumuşak doku desteği ve kemiğin anatomik çıkıntısına dayanmaksızın farklı açılarda tespit sağlayamamaktadır. Kırık tespiti sırasında her zaman bu gibi yardımcı unsurların olmaması bize farklı açılarda uygulanabilen ve daha stabil kablo fiksasyon sisteminin gereksinimi düşündürmüştür.

Kablo fiksasyonu yaygın cerrahi yöntem olarak kullanılmakla birlikte, uygulama bölgesinde var olan intrameduller protez yada fiksasyon materyali sonrası, ortaya çıkan kırığın yada osteotominin fiksasyonunda kablo sistemi neredeyse tek seçenek haline gelmektedir. Biz de çalışmamızda özellikle periprostetik femur kırıklarında ve revizyon protez cerrahisinde sıkça kullanılan çevresel tel tespitinin çok düzlemli kablo fiksasyon sistemi ile daha stabil ve güvenli olabileceğini düşünmekteyiz.

Uzun kemiklerin metafizo-diafizeal uzun oblik ya da spiral kırıklarda uygulanan kablo fiksasyon sisteminin bölgenin konik yapısından dolayı germe işlemi sırasında diafizer bölgeye doğru yer değiştirdiği ve domino sıkıldıktan sonra da gevşediği görülmektedir

Postoperatif periprostetik femur kırıklarının fiksasyon yöntemlerini karşılaştıran birçok klinik ve biyomekanik çalışma yapılmıstır [11-15]. İntraoperatif proksimal femur kırıklarının tedavi yöntemleriyle ilgili klinik çalışmalar varsa da biyomekanik çalışma yoktur [11, 16-18]. Bu tip kırıkların tedavisinde kullanılan tespit yöntemlerinin ameliyat sonrası erken dönemde sağladıkları stabilite konusunda çalışma yapılmamış olması 
rehabilitasyon planlanması açısından sorun yaratması nedeniyle önemli bir sorun oluşturmaktadır. Çok düzlemli kablo fiksasyon sistemi ile stabilite ve devamlılığının sağlanması rehabilitasyon planlanmasının erken yapılmasına olanak sağlayacağını düşünmekteyiz.

Yapılan klinik çalışmaların çoğunda ameliyat sırasında proksimal femurda oluşan doğrusal kırığın tedavisi için serklaj teli kullanıldığı bildirilmektedir $[8,9,19,20]$. Shaw ve Daubert [21], çelik tel, parham band, titanyum kablo, propilen ve naylon bandın oluşturdukları kompresyonu test ettikleri biyomekanik çalışmada kablo ve Parham bantlarının diğer yöntemlere olan üstünlüğünü ortaya koymuşlardır. $\mathrm{Bu}$ nedenle çalışmamızda test ettiğimiz gruplar arasına çelik serklaj teli ile fiksasyon yöntemi dahil edilmemiş, sadece standart kablo ve çok düzlemli kablo fiksasyon sistemi yöntemleri karşılaştırılmıştır

Çok düzlemli kablo fiksasyon sistemi ile uzun kemik metafizer metafizo-diafizeal uzun oblik yada spiral kırıklarda, osteotomilerde, revizyon protez cerrahisindeki uzatılmış trokanterik osteotomiler de, periprostetik kırıklarda kullanılması tespit stabilitesinde ve devamlılığının korunmasında anlamlı artış olacağını düşünmekteyiz. Kontrol grubu olarak başta interfragmenter tespit ile karşılaştırma yapmak istesek te özellikle kablo sisteminin sıkça kullanıldığı periprostetik kırıklar gibi meduller kanalın işgal edilmiş olduğu kırıklarda interfragmenter tespit uygulanamayacağ 1 için standart kablo fiksasyonun daha anlamlı bir karşılaştırma olabileceğini düşündük.

Koyama ve ark. [22] 62 revizyon kalça artroplasti vakalarında yapmış olduğu trokanter major osteotomi sonrasi kablo fiksasyonun medial kortekse dayandırılan grupta kaynamama oranının, medial kortekse drilleme yapılıp kablo uygulanan gruba göre yüksek olduğunu tespit ettiler. Bu nedenle kablo fiksasyonunda longitudinal mobilite önlemek için kablonun drill deliğinden geçilmesi gerekliliğini vurgulamışlardır. SKF sisteminde kablo migrasyonunu önlemek için yumuşak dokulardan, kemiğin anatomik çıkıntılarından veya kemik kortekse kanallar açıp bu kanallardan geçilerek ya da bir diğer fiksasyon sistemine (plak-vida) bağlanarak destek sağlanmaktadir. ÇDKF sistemde ise aparatlar da bulunan dikenler sayesinde kemik üzerinde bikortikal destek sağlayıp, migrasyon olasılığını da en aza indirmekte olup migrasyonu önleyici yardımcı unsurlara da gerek kalmadan kemiğin her hangi bir bölgesine uygulanabilmektedir. ÇDKF sistemindeki aparatlar çalışmamız sırasında bütün olarak kullanılmakla birlikte uygulama alanına göre birbirinden bağımsız olarakta kullanılabilir yapıdadır.

Sandhu ve ark. [23] 20 periprostetik femur kırıklı vaka çalışmasında tek başına kablo fiksasyonun torsiyonel stabiliteyi sağlayamadığını bu yüzden plak vida sistemi ile kombine kullanılması gerekliliğini vurgulamışlardır. SKF sistemi kemik kortekse integre olmadığı için aynı bir parmaktaki yüzük gibi rotasyonel stabilite sağlayamamaktadır. ÇDKF sistemi hem medialde hemde lateralde dikenleri ile kortekse tutunduğundan rotasyonel stabiliteyi sağlayabileceğini düşünmekteyiz. Ancak çalışmamızda bunu test edemedik.

SKF sisteminde yardımcı unsurlar olmadan kablonun değişik açılarla konması nerede ise imkansız iken ÇDKF sistemi kablolarını kırığa dik, yatay düzlemle 45 derece açı olacak şekilde koyarak sistemin en zor şartlardaki dayanıklılığını kompresyon testi ile karşılaştırmak istedik. ÇDKF sistemi istenilen açıda fiksasyona izin vermektedir. Biz çalışmamızda osteotomi hattına dik konumda fiksasyonu amaçladık. Bununda kompresyonu maksimum sağlayacağını düşündük.

Çalışmamızda grupların tespit sonrası elle yapılan rotasyonel hareket kontrolünde, ÇDKF sistemde hiçbir hareket gözlenmese de sistemlerin stabilitelerinin belirlenebilmesi için sadece aksiyel yüklenme testlerinin yapılması, rotasyonel yüklenme testlerinin, üç nokta eğilme testlerinin ve değişik açılarda femoral yüklenmelerin teknik imkansızlıklar nedeniyle yapılamamış olması çalışmamızın önemli eksikliklerindendir. Bununla birlikte oluşturulan modelde kas ve ligaman yapılarının sisteme yapacağı etkinin test edilememesi bir diğer eksikliktir. Bu unsurların model oluşturulurken sisteme dahil edilmesiyle, 
uygulanan tedavi yöntemlerinin sağladığı stabilite konusunda daha ayrıntılı veriler elde edilebilineceğini düşünmekteyiz.

Bir kırık fiksasyonunda sistemin dayanıklılığının test etmenin en önemli 3 yöntemi; 3 nokta ya da 4 nokta bükülme testi (bending test), rotasyonal stres testi ve kompresyon testidir. Biz Sivas koşullarında ilk 2 testi uygulayamadık. ÇDKF sisteminin dayanıklılığ ve etkinliğini tam değerlendirmek için bu 2 yöntemin de test edilerek gözlenmesi gerekmektedir.

Sonuç olarak, çok düzlemli kablo fiksasyon sisteminin standart kablo fiksasyon sistemine göre aksiyel kompresyon testinde anlamlı olarak üstün olduğunu göstermiştir. Kırık ya da osteotomi hattının çok düzlemli uzanımlarının önceden öngörülememesi, SKF sisteminin tek bir düzlemde fiksasyona izin vermesi ve metafizer metafizo-diafizer bölgede gevşemesi nedeni ile ÇDKF sistem ile bu sorunların giderilmesinde mutlak bir üstünlük sağlamaktadır. ÇDKF sisteminin dikenleri sayesinde rotasyonel stabilite etkisinin tespiti için rotasyonel yüklenme testlerinin yapılması, sistemin gücünü göstermede daha anlamlı olacağını düşünmekteyiz.

\section{Kaynaklar}

1. Gruen TA, McNeice GM, Amstutz HC. "Modes of failure" of cemented stemtype femoral components: a radiographic analysis of loosening. Clin Orthop Relat Res 1979; 141:17-27.

2. Parrish TF, Jones JR. Fracture of the femur following prosthetic arthroplasty of the hip. report of nine cases. J Bone Joint Surg Am 1964; 46: 241-8.

3. Campbell P, McWilliams TG. Periprosthetic femoral fractures. Current Orthopaedics 2002; 16: 126-32.

4. Berry DJ. Epidemiology: hip and knee. Orthop Clin North Am 1999; 30:183-90.

5. Fink B, Fuerst M, Singer J. Periprosthetic fractures of the femur associated with hip arthroplasty. Arch Orthop Trauma Surg 2005; 125: 433-42.

6. Brady OH, Garbuz DS, Masri BA, Duncan CP. The treatment of periprosthetic fractures of the femur using cortical onlay allograft struts. Orthop Clin North Am 1999; 30: 249-57.

7. Greidanus NV, Mitchell PA, Masri BA, Garbuz DS, Duncan CP. Principles of management and results of treating the fractured femur during and after total hip arthroplasty. Instr Course Lect 2003; 52: 309-22.

8. Mallory TH, Kraus TJ, Vaughn BK. Intraoperative femoral fractures associated with cementless total hip arthroplasty. Orthopedics 1989; 12: 231-9.

9. Johansson JE, McBroom R, Barrington TW, Hunter GA. Fracture of the ipsilateral femur in patients wih total hip replacement. J Bone Joint Surg Am 1981; 63: 1435-42.

10. John J, Callaghan MD, Aaron G, Rosenberg MD, Harry E, Rubash MD. The Adult Hip, Çeviri Editörü: Erişkin Kalça, Mustafa ÖZKAN-Meriç ÜNAL, Doğan Tıp Kitabevi, II. Bask1, II. Cilt, Bölüm 2007; 83: 1252.

11. Kaab MJ, Stöckle U, Schütz M, Stefansky J, Perka C, Haas NP.Stabilisation of periprosthetic fractures with angular stable internal fixation: a report of 13 cases. Arch Orthop Trauma Surg 2006; 126: 105-10.

12. Haddad FS, Marston RA, Muirhead-Allwood SK. The Dall-Miles cable and plate system for periprosthetic femoral fractures. Injury 1997; 28: 445-7.

13. Tsiridis E, Haddad FS, Gie GA. Dall-Miles plates for periprosthetic femoral fractures. A critical review of 16 cases. Injury 2003; 34: 107-10.

14. Haddad FS, Duncan CP, Berry DJ, Lewallen DG, Gross AE, Chandler HP. Periprosthetic femoral fractures around well-fixed implants: use of cortical onlay allografts with or without a plate. J Bone Joint Surg Am 2002; 84: 945-50.

15. Wang JW, Wang CJ. Periprosthetic fracture of the femur after hip arthroplasty: The clinical outcome using cortical strut allografts. J Orthop Surg (Hong Kong) 2000; 8: 27-31. 
16. Eckardt A, Aberman HM, Cantwell HD, Heine J. Biological fixation of hydroxyapatite-coated versus grit-blasted titanium hip stems: a canine study. Arch Orthop Trauma Surg 2003; 123: 28-35.

17. Ko PS, Lam JJ, Tio MK, Lee OB, Ip FK. Distal fixation with Wagner revision stem in treating Vancouver type B2 periprosthetic femur fractures in geriatric patients. J Arthroplasty 2003; 18: 446-52.

18. Berend KR, Lombardi AV Jr, Mallory TH, Chonko DJ, Dodds KL, Adams JB. Cerclage wires or cables for the management of intraoperative fracture associated with a cementless, tapered femoral prosthesis: results at 2 to 16 years. J Arthroplasty 2004; 19: 17-21.

19. Tsiridis E, Haddad FS, Gie GA. The management of periprosthetic femoral fractures around hip replacements. Injury 2003; 34: 95-105.

20. Fitzgerald RH Jr, Brindley GW, Kavanagh BF. The uncemented total hip arthroplasty. Intraoperative femoral fractures. Clin Orthop Relat Res 1988; 235 : 61-6.

21. Shaw JA, Daubert HB. Compression capability of cerclage fixation systems. A biomechanical study. Orthopedics 1988; 11: 1169-74.

22. Koyama K, Higuchi F, Kubo M, Okawa T, Inoue A. Reattachment of the greater trochanter using the dall-miles cable grip system in revision hip arthroplasty. J Orthopaedic science 2001; 6: 22-7.

23. Sandhu R, Avramidis K, Johnson-Nurse C. Dall-Miles cable and plate fixation system in the treatment of periprosthetic femoral fractures: a review of 20 cases. J orthopaedic Surgery 2005; 13: 259-66. 